\title{
Tratamento não cirúrgico de extensa lesão periapical: relato de caso
}

Non-surgical treatment of extensive apical periodontitis: case report

FERNANDES, Samuel Lucas'; MARTINS, Milena Perraro²; BARROS, Monize Bernardes ${ }^{3}$, BOER, Nilton César Pezati; DUARTE, Marco Antonio Hungaro $^{5}$

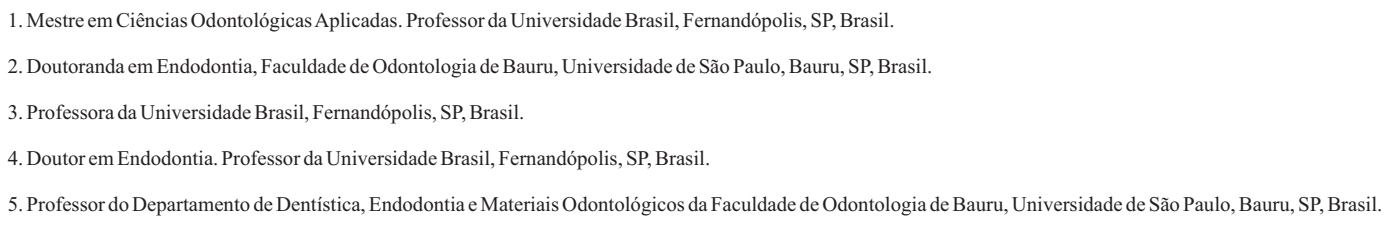

2. Doutoranda em Endodontia, Faculdade de Odontologia de Bauru, Universidade de São Paulo, Bauru, SP, Brasil.

3. Professora da Universidade Brasil, Fernandópolis, SP, Brasil.

4. Doutor em Endodontia. Professor da Universidade Brasil, Fernandópolis, SP, Brasil.

5. Professor do Departamento de Dentística, Endodontia e Materiais Odontológicos da Faculdade de Odontologia de Bauru, Universidade de São Paulo, Bauru, SP, Brasil.

Endereço para correspondência:

Samuel Lucas Fernandes

Faculdade de Odontologia de Bauru - USP

Disciplina de Endodontia

Alameda Doutor Octávio Pinheiro Brisolla, 9-75

17012-901 - Bauru - São Paulo - Brasil

E-mail: samuel.lukas.usp@gmail.com

Recebido: 26.10 .2017

Aceito: 12.11.2017

\section{RESUMO}

$\mathrm{O}$ tratamento endodôntico de dentes associados às lesões periapicais extensas geralmente envolve um longo período de acompanhamento e o reparo ósseo completo nem sempre ocorre. Este trabalho tem como objetivo a exposição de um caso clínico de lesão periapical extensa, tratado sem a necessidade de complementação cirúrgica.

Palavras-chave: Necrose da polpa dentária. Cavidade pulpar. Endodontia.

\section{ABSTRACT}

Endodontic treatment of teeth associated with extensive periapical lesions usually involves a long period offollow-up and complete bone repair does not always occur. This paper aims to expose a clinical case of extensive periapical lesion, treated without the need for surgical complementation.

Keywords: Dental pulp necrosis. Dental pulp cavity. Endodontics. 


\section{INTRODUÇÃO}

As infecções endodônticas decorrem de diversos fatores como a cárie dentária ou os traumatismos alvéolodentários ${ }^{1}$. A contaminação e a prevalência de biofilme no interior dos canais radiculares propiciará a reação inflamatória dos tecidos periapicais, gerando o aparecimento de lesões peripicais2. Essa é uma reação tem como função conter a propagação da infecção, entretanto não exercem o papel de eliminação da infecção3. Um estudo analisando 256 lesões periapicais contatou que metade das lesões se constituíam de granulomas, $35 \%$ de abcessos e $15 \%$ de cistos ${ }^{4}$.

O tratamento endodôntico tem como objetivo eliminar a infecção e propiciar a cura das lesões peripicais5. Atualmente uma infinidade de instrumentos tem sido desenvolvida a fim de facilitar o preparo dos canais radiculares, dentre eles os sistemas reciprocantes propiciam o preparo dos canais com um único instrumento, demandando um curto período de tempo para a instrumentação ${ }^{6-7}$. Com isso se tem um tempo maior durante o atendimento para a realização de protocolos modernos de irrigação, aplicando métodos adicionais e propiciando uma melhor limpeza quando comparada a irrigação convencional $^{8-12}$. A finalização do tratamento endodôntico se dá ao final do processo de limpeza e desinfecção e necessita de condições clínicas para a obturação como a possibilidade do controle de humidade no interior do canal radicular e a ausência de sintomatologia. Apesar de controvérsias sobre a finalização de casos de necrose pulpar em uma única sessão ${ }^{13}$, sabe-se que nem todos os casos podem ser finalizados desta forma. A medicação intracanal é de suma importância entre as sessões, sendo a pasta de hidróxido de cálcio amplamente empregada com esta função mostrando excelentes resultados clínicos14. Este artigo tem por objetivo relatar o tratamento via canal de uma extensa lesão apical utilizando-se de instrumento único para a modelagem do canal radicular e métodos complementares para a desinfecção.

\section{RELATO DE CASO}

A paciente do sexo feminino e 27 anos de idade compareceu à clínica, queixando-se de dor e apresentou edema na metade posterior esquerda do palato, mole a palpação. A paciente relatou que o dente estava aberto há mais de um ano em tratamento.

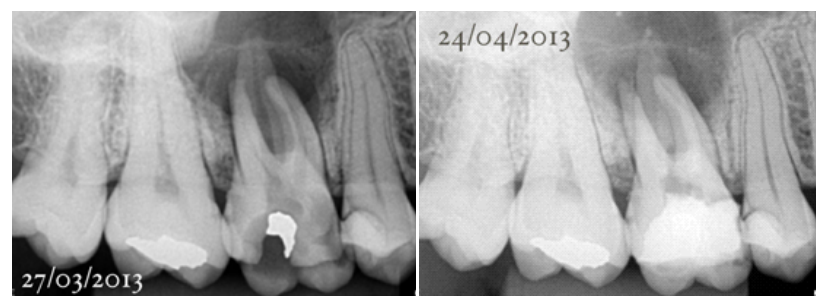

Figura 1 - Radiografia inicial. Radiografia após trinta dias de evolução do caso.

E o plano de tratamento adotado, foi a reintervenção endodôntica. Em uma primeira sessão foi realizado o acesso aos canais do dente 26, localizando 4 canais (MV1, MV2, DV, P), instrumentando os canais com limas Reciproc R25 (VDW, Alemanha) e irrigação com solução fisiológica, descompressão do palato e aspiração absoluta, utilizando pontas capilary Tips. Como medicação intracanal, foi utilizado a pasta de hidróxido de cálcio (Ultracal) e selamento com coltosol e resina composta. Após 30 dias, na segunda sessão o dente foi reaberto, irrigado com hipoclorito de sódio $2,5 \%$, e realizado a agitação ultrassônica (PUI) da solução irrigadora por 3 vezes de 30 segundos por canal. Foi colocada medicação intracanal por mais 60 dias (Ultracal). Na terceira sessão a medicação foi removida e o dente foi obturado com cones específicos e cimento AH Plus (Dentsply).

$\mathrm{O}$ caso foi acompanhado por dois anos e verificou-se um completo reparo apical e ausência de sintomatologia dolorosa aos testes de percussão vertical e lateral.

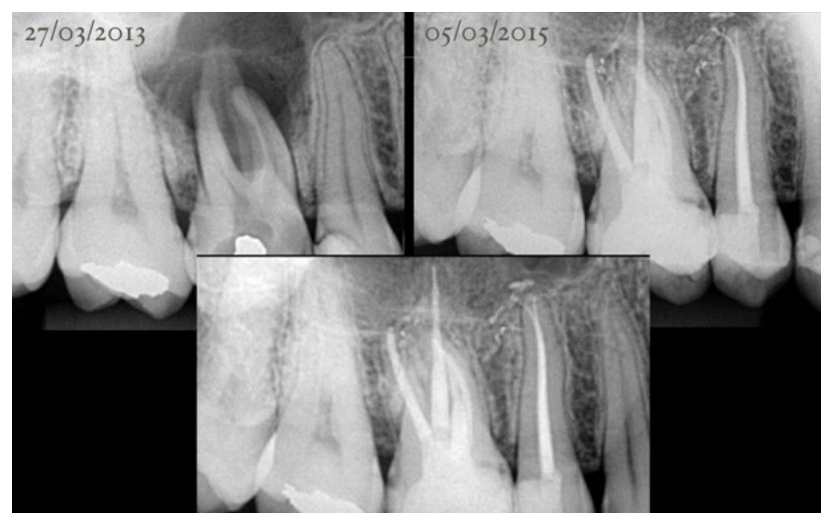

Figura 2 - Radiografia final, após a obturação e selamento coronário.

\section{DISCUSSÃ0}

A tomada de decisão é sempre dependente da complexidade do caso $^{15}$, para se delinear um plano de tratamento deve-se verificar as condições da patologia apresentada, capacidade profissional e as expectativas do 
paciente em relação ao caso. Neste caso as possibilidades de re-intervenção via canal radicular e a opção da complementação cirúrgica foi exposta ao paciente, que optou pela intervenção via canal radicular e aguardar a proservação. A abordagem conservadora, apesar do tamanha da lesão, mostrou-se eficiente para a resolução do caso.

Essa resolução se deve ao fato de conseguir a sanificação do sistema de canais radiculares. Para tal, o emprego do hipoclorito de sódio como substância irrigadora principal, mostrou-se eficiente, na promoção da limpeza e desinfecção, mostrando um potencial já conhecido de efetividade para a limpeza ${ }^{16}$. E a ativação ultrassônica que têm mostrado um excelente potencial de limpeza foi empregada, potencializando o uso dessa substância. O uso da clorexidina é indicada como substância irrigadora, e esta pode ser uma alternativa, todavia neste caso não foi empregada ${ }^{17}$.

Como a paciente chegou com dor ao consultório e com a presença de uma extensa lesão, optou-se pela realização da medicação intracanal sendo em pregado a pasta de hidróxido de cálcio, que cumpre bem os papeis necessários de uma boa medicação entre as sessões e na segunda troca de medicação pode-se observar uma boa condição de limpeza e ausência de sintomatologia espontânea e à percussão vertical e horizontal, mostrando uma boa condição de saúde do periodonto apical e lateral. O hidróxido de cálcio é a medicação intracanal mais indicada, e tem mostrado bons resultados no tratamento de lesões extensas, ${ }^{17}$ mostrando resultados compatíveis com os encontrados neste caso clínico. Quando o hidróxido de cálcio foi empregado apenas em uma semana não correspondeu com as expectativas de desinfecção ${ }^{16}$.

$\mathrm{O}$ uso da medicação intracanal entre as sessões é motivo de muita discussão, todavia o que se pode afirmar é que nas regiões de complexidades anatômicas como ramificações apicais e istmos a limpeza é deficiente. E que a medicação intracanal tem papel fundamental na redução da infecção microbiana ${ }^{18}$. Assim como em outros estudos o tratamento não cirúrgico de uma extensa lesão periapical respondeu de forma satisfatória ${ }^{16-17}$.

\section{CONCLUSÃO}

O tratamento endodôntico, via canal, utilizando-se de da irrigação convencional associada ao PUI e de medicação intracanal com hidróxido de cálcio, possibilitou uma desinfecção do canal radicular o suficiente para propiciar o completo reparo periapical.

\section{REFERÊNCIAS}

1. Ghorbanzadeh S, Ashraf H, Hosseinpour S, Ghorbanzadeh F. Nonsurgical management of a large periapical lesion: a case report. Iran Endod J. 2017;12(2):253-6.

2. Möller AJ, Fabricius L, Dahlén G, Ohman AE, Heyden G. Influence on periapical tissues of indigenous oral bacteria and necrotic pulp tissue in monkeys. Scand J Dent Res. 1981;89(6):475-84.

3. Nair P. Pathobiology of primary apical periodontitis. Pathwayof the pulp. 9th ed. St. Lous: CV Mosby; 2006. p. 541-2.

4. Nair PN, Pajarola G, Schroeder HE. Types and incidence of human periapical lesions obtained with extracted teeth. Oral Surg Oral Med Oral Pathol Oral Radiol Endod. 1996;81(1):93-102.

5. Sjögren U, Figdor D, Persson S, Sundqvist G. Influence of infection at the time of root filling on the outcome of endodontic treatment of teeth with apical periodontitis. Int Endod J. 1997;30(5):297-306.

6. Bartols A, Laux G, Walther W. Multiple-file vs. single-file endodontics in dental practice: a study in routine care. PeerJ. 2016;4:e2765.

7. Bartols A, Reutter CA, Robra BP, Walther W. Reciproc vs. hand instrumentation in dental practice: a study in routine care. PeerJ. 2016;4:e2182.

8. Prado MC, Leal F, Gusman H, Simão RA, Prado M. Effects of auxiliary device use on smear layer removal. J Oral Sci. 2016;58(4):561-7.

9. Muhammad OH, Chevalier M, Rocca JP, Brulat-Bouchard N, Medioni E. Photodynamic therapy versus ultrasonic irrigation: interaction with endodontic microbial biofilm, an ex vivo study. Photodiagnosis Photodyn Ther. 2014;11(2):171-81

10. Ismail PM, Ahamed S, Sabiha PB, Sekhar MC, Moosani G, Reddy $\mathrm{SN}$, et al. Comparison of sealer penetration by using different irrigation techniques - an in-vitro study. J Clin Diagn Res. 2016;10(12):ZC50-3

11. Spoorthy E, Velmurugan N, Ballal S, Nandini S. Comparison of irrigant penetration up to working length and into simulated lateral canals using various irrigating techniques. Int Endod J. 2013;46(9):815-22.

12. Haapasalo M, Shen $\mathrm{Y}$, Wang $\mathrm{Z}$, Gao Y. Irrigation in endodontics. Br Dent J. 2014;216(6):299-303

13. Schwendicke F, Göstemeyer G. Cost-effectiveness of single- versus multistep root canal treatment. J Endod. 2016;42(10):1446-52.

14. Kumar GV, Hegde RS, Moogi PP, Prashant BR, Patil B. Nonsurgical management of large periapical lesion in mature and immature teeth using different calcium hydroxide formulations: case series. J Contemp Dent Pract. 2013;14(6):1183-8.

15. Jawad S, Taylor C, Roudsari RV, Darcey J, Qualtrough A. Modern endodontic planning part 1: assessing complexity and predicting success. Dent Update. 2015;42(7):599-600.

16. Waltimo T, Trope M, Haapasalo M, Ørstavik D. Clinical efficacy of treatment procedures in endodontic infection control and one year follow-up of periapical healing. J Endod. 2005;31(12):863-6.

17. Oztan MD. Endodontic treatment of teeth associated with a large 
Tratamento não cirúrgico de extensa lesão periapical: relato de caso

periapical lesion. Int Endod J. 2002;35(1):73-8.

18. Vera J, Siqueira JF Jr, Ricucci D, Loghin S, Fernández N, Flores B, et al. One- versus two-visit endodontic treatment of teeth with apical periodontitis: a histobacteriologic study. J Endod. 2012;38(8):1040-52. 